\title{
Kinematic parameters determination of the drilling equipment designed to work in slope degraded terrains
}

\author{
Alexandra Liana Vișan ${ }^{1 *}$, Gabriel Constantin Bogdanof ${ }^{1}$, Dumitru Milea ${ }^{1}$, Radu Ciupercă ${ }^{1}$ \\ and Gabriel Gheorghe ${ }^{1}$.
}

${ }^{1}$ INMA Bucharest, Research Development Innovation Department, 6 Ion Ionescu de la Brad, Romania

\begin{abstract}
This paper aims to present the cinematic parameters determination of a drilling equipment design to work in slope degraded terrains, based on field experimental data acquired in normal exploitation condition and also in heavy environmental conditions. This equipment is developed in order conduct forestation and rehabilitation works of degraded lands and to be incorporated on innovative planting technology (degraded soil processing, levelling and terrace surface modelling, planting settlement, etc). This technology answers to the need to implement measures of environmental rehabilitation and enhancement of slopedegraded forestlands, by development several performing equipments that answer to technological needs of this works (land stability, terrace dimensions, type of power source and seedlings planting variety) in order to rise to the performances and to respect the labour safety standards under difficult working conditions. Also, here in presented equipment has a great impact on forestry and pomiculture works, and also on environmental technical works meant to improve soil quality, lowering the surface and depth erosion, rainwater capitalization, lowering the dust pollution and natural calamity risk, and at last to rehabilitate the inland flora.
\end{abstract}

\section{Introduction}

In Romania, lately are made considerable efforts and a large campaign, by civil society and to stop the illegal deforestation and to protect protected areas, but also the virgin forest and natural parks, Fig. 1. The national territory, covered with forest has decreased at 28.95 $\%$ (approx. 7 million ha), figure that is lower than the UE average that is $43 \%$. A significant part of it, approx. 415,000 ha, belong to small owners (areas smaller than 100 ha) which are poorly administered and exposed of illegal cuts. If we refer to virgin and quasi-virgin forests, areas in which the nature has its one rules of development and without human intervention, is estimated at 3\% from the total forest lands, compared to $12 \%$ form 1974, and many of them represent secular oak forests were included in UNESCO Mondial Patrimony. [1]

\footnotetext{
* Corresponding author: alexandrion1982@gmail.com
} 
The yellow areas from Fig.1, represent low risk level for framing sector and involves form authorities' point of view, close monitorization, the red areas represents significant risk level for framing and involves control plans foundation regarding the implementation EUTR (European Union Regulation on Wood Trade), respectively to: evaluate periodic the risks in those area; to identify them and to establish the appropriate measures to mitigate them.[2]

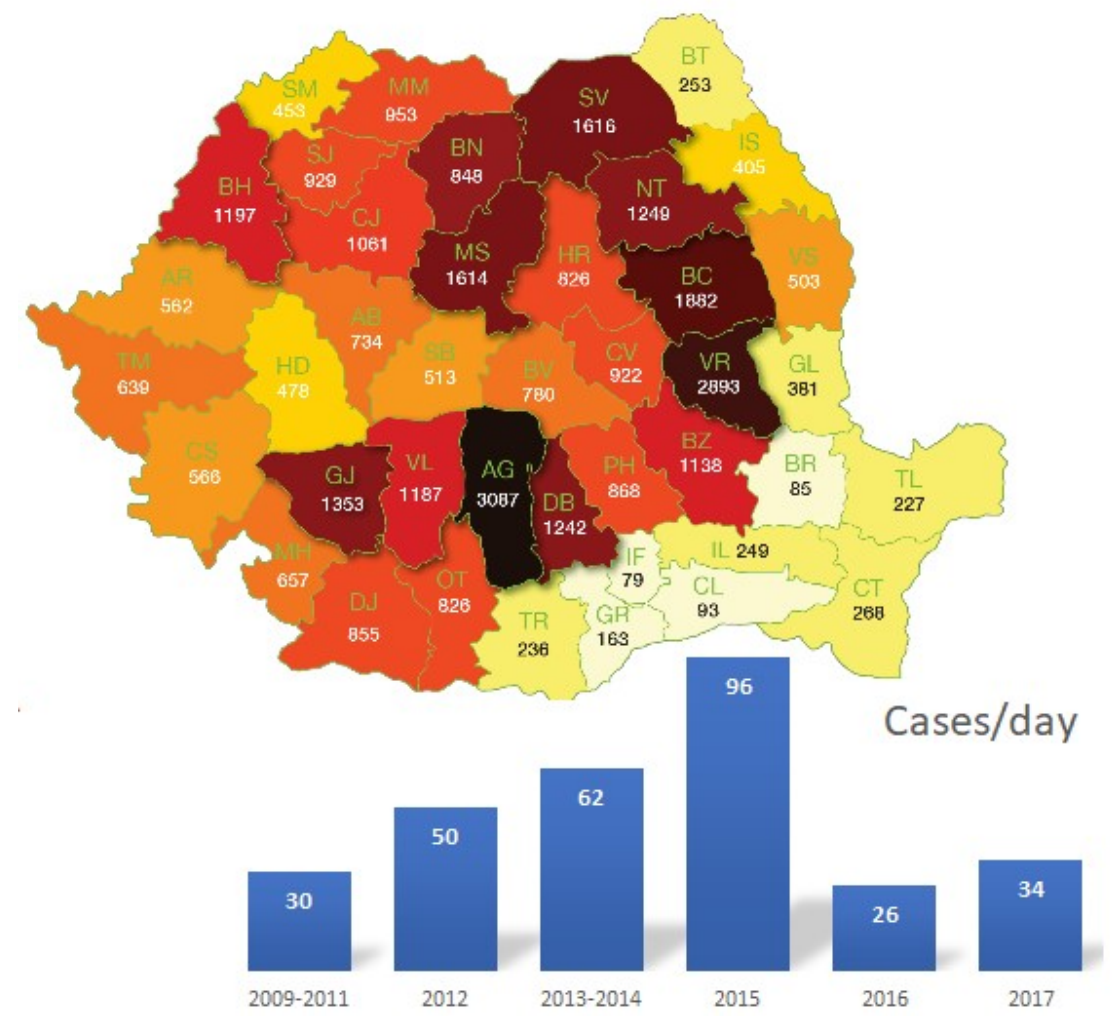

Fig.1 Romanian reginal map of illegal deforestation in 2015 and its evolution until 2017 [3,4]

\section{Methods to mitigate the environmental and ecologic risks}

Making the correlation between those two official statistics, it can be concluded that, the regions with highest illegal cutting cases/day are the regions with highest risk (respectively Gorj- GJ., Vâlcea - VL., Arges - AG., Vrancea - VR., Bacau-BC., Neamt - NT., Suceava SV., Bistrita-Nasaud - BN. and Mures - MS.) which are mainly situated in hilly and mountain landscapes, fact which implies that the risk assessment depends on soil erosion and landslides. Analysing, also the maps regarding those evaluations [5, 6], was noticed that those regions are also with high risk and for this reason the mitigation measures that can be implemented in deforestation terrains can be adequate.

Apart from the legislative measures that are supported by WWF (World Wide Fund for Nature), another only way to mitigate the forest loss and the environmental risks, is to restore the forests on degraded lands by, two technologic processes, respectively afforestation and reforestation. The difference of those terms is the afforestation represents conversion of other land-uses into forest, while reforestation is re-establishment of forest formations. [7] 


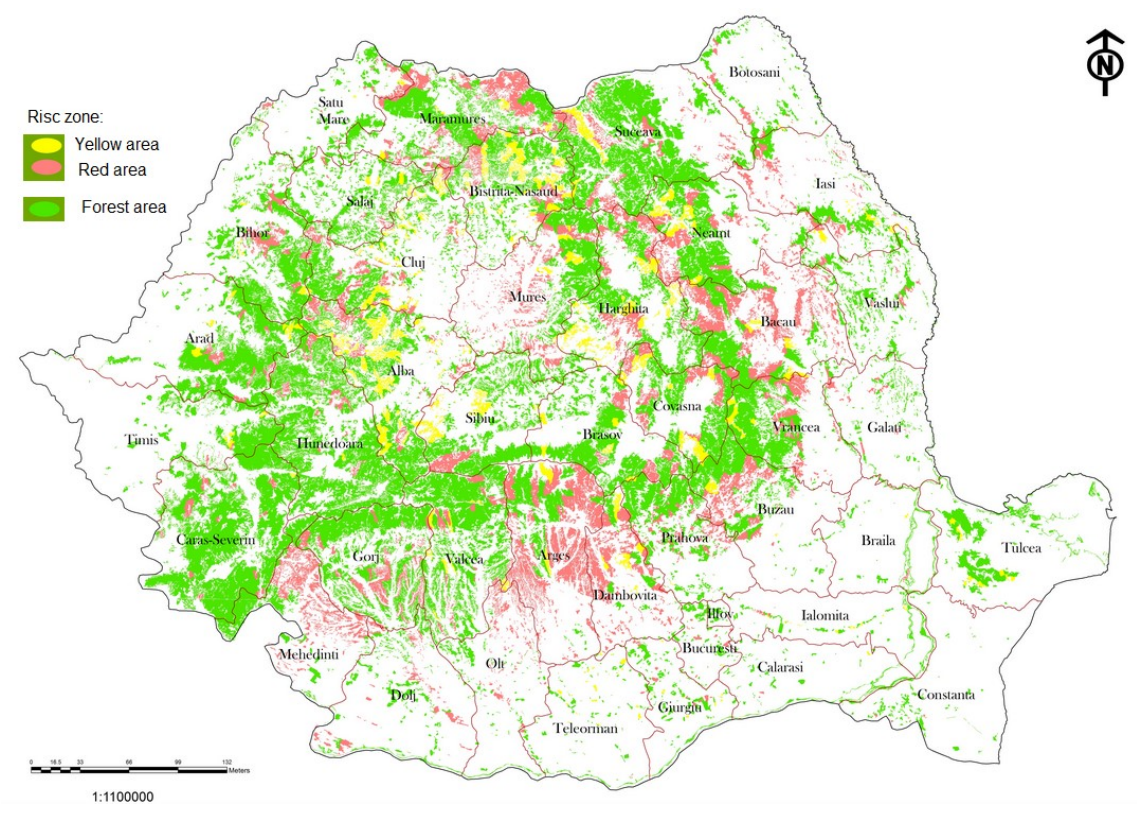

Fig.2. Risk map regarding the illegal cuttings [4]

Taking in to consideration the fact that every area has a specific fauna that makes part of an ecologic group, INMA Bucharest has develop an innovative afforestation technology that can be adapted to technical-forest measures to regenerate or to plant autotune trees and shrubs in order to increase the productivity and to reduce the human labour. $[8,9,10]$ More than that, the mechanized operations developed had taken in to consideration the soil quality, because, first of all the ground must ensure the aggregate equipment stability during operation, secondly the operator safety and thirdly the optimal condition to develop the seedlings. In order to re-establish the soil stability (in slope degraded terrains mountain and hilly areas) it is necessary to be accomplish specific works that have a high efficiency in diminishing superficial leakage and retention water. The most efficient slopes proved to be terraces with platform in the contraption, especially during the establishment period (spring and autumn) and for this reason the drilling equipment comply specific requirements and must incorporate special systems in order to adapt to terrace angle and seedling type (with nude rooted or with earth bale) as: Auger position adjustment system used to make platting pits on sloping land [11], system for rapid mounting and damping the axial shocks of the drill for making the planting holes [12]; deviations compensation device during the drilling process using a guided auger by parallelogram mechanism [13].

In order to establish the drilling aggregate performance were performed several experimental tests in relevant conditions, namely in ground land and in cultivated land. The firs condition (ground land) is representative because in some cases the land owner do not consider to make land improvement works (scarifying, milling and levelling) and the other one when the soil it requires them.

\section{Experimental procedure and equipment's used}

The aggregate is made from small gauge power source, 318 BERTOLINI motocultivator type of $19 \mathrm{HP}$, equipped with an innovative drilling equipment - BM [7,11] designed to work in difficult soil conditions in order to generate seedling dwellings. In Fig.3, are presented three imagines regarding the tested equipment: a - drilling equipment, $\mathrm{b}$ - working aggregate, $\mathrm{c}$ - specific adjustments for auger inclination. 


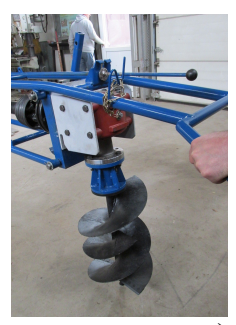

a)

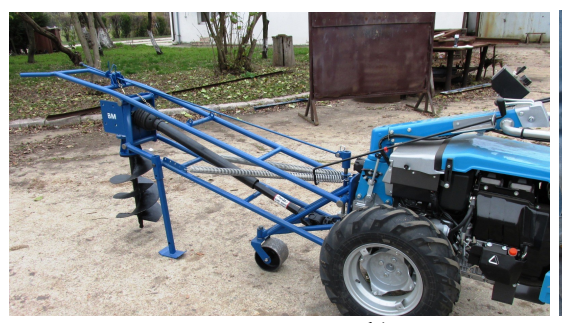

b)

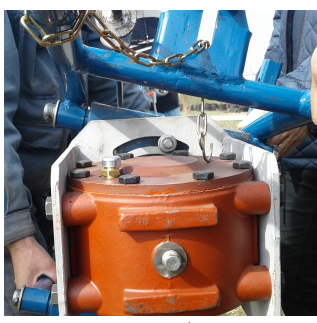

c)

Fig.3. The drilling equipment working in aggregate with the power source

The BM equipment weights max. $112 \mathrm{~kg}$ and is provided with two earth augers of $\varnothing$ 300 and $\varnothing 400 \mathrm{~mm}$, that can work at $300 \mathrm{~mm}$ and $400 \mathrm{~mm}$ depth. The augers are guided by the adjusting position system (designed for max. $30^{\circ}$ left and right inclination), in order to achieve vertical planting holes regardless of the terrace counter-slope. The auger working speed is controlled by the human operator, using the motocultivator acceleration handle and its powered only when the auger is positioned on the soil surface, the maximum rotation speed is 135 rot. $\mathrm{min}^{-1}$. This equipment is required to be handled by two workers who have been previously trained and familiarised with this equipment. One to serve the motocultivator - controlling the auger speed, and the other the BM equipment - controlling the auger working parameters (the hole depth and the earth drilling speed).

The data from the experimental field activity was carryout the measuring instruments from Table 1.

Table 1. Measuring instruments used on experimental field.

\begin{tabular}{|c|c|c|}
\hline Measuring instruments & Measuring range & Precision \\
\hline Weighing machine & $0 \div 150[\mathrm{~kg}]$ & $0.01[\mathrm{~g}]$ \\
\hline Digital timer & $0 \div 30[\mathrm{~min}]$ & $0.2[\mathrm{~s}]$ \\
\hline Soil Compact Meter SC $900-$ Spectrum & $0 \div 45[\mathrm{~cm}], 0 \div 7000[\mathrm{kPa}]$ & $\pm 1.25[\mathrm{~cm}], \pm 103[\mathrm{kPa}]$ \\
\hline Hygrometer HH-2 & $0 \div 50 \%$ & $\pm 3 \%$ \\
\hline Roulette & $0 \div 8[\mathrm{~m}]$ & $0.5[\mathrm{~mm}]$ \\
\hline Dynamometer & $0 \div 300[\mathrm{daN}]$ & $\pm 5[\mathrm{daN}]$ \\
\hline Level indicator & $1.5[\mathrm{~m}]$ & \\
\hline Linear & $2[\mathrm{~m}]$ & \\
\hline Graduated glass & $500[\mathrm{ml}]$ & \\
\hline
\end{tabular}

The first step in the experimental procedure was to measure the physic-mechanical soil properties as: compaction and humidity measurements at different depths. The measurements were made for two land strips: on cultivated (CL) and grounded land (GL), and the results are presented in Fig.4.
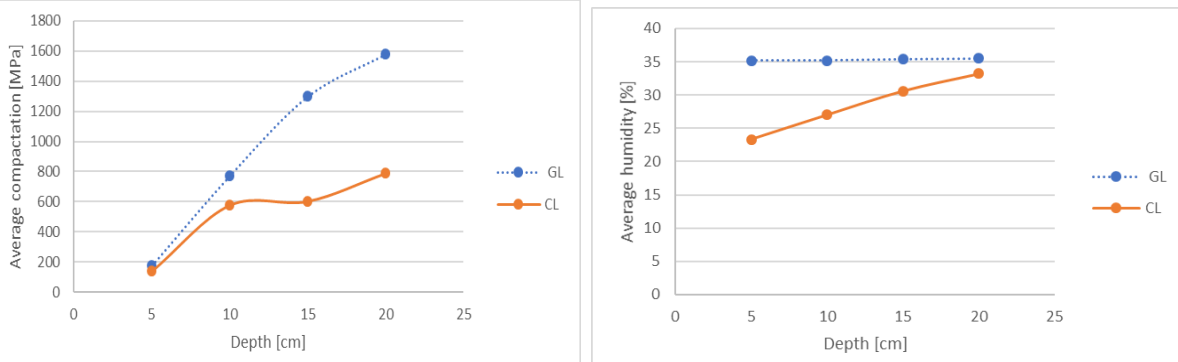

Fig.4. The soil proprieties for grounded land - GL and cultivated land - CL. 
After that, the aggregate is moved into the experimental field, where had been created terraces with various slope, respectively 0,15 and $20^{\circ}$, and for each case are made three determinations. In Fig.5.a, is presented an image from the experimental field for a terrace of $20{ }^{0}$ slope, on which was previously cultivated (milled and levelled).

Another case is the one on which the aggregate is used on slope lands were have not been made soil works and for this reason is covered with vegetation. This case study is important to test the technical limitations and working limits. In Fig.5.b, is presented an image from the testing ground that had a slope of $20^{\circ}$.

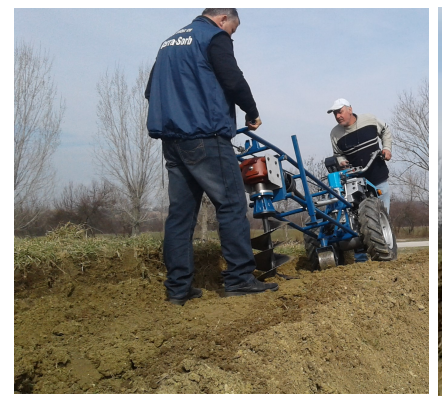

a)

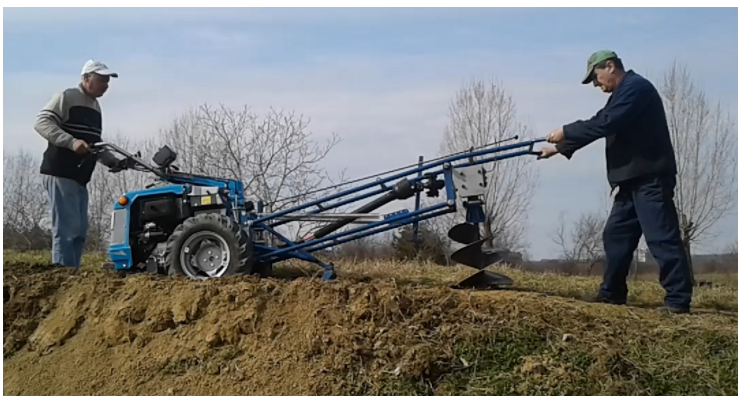

b)

Fig.5 Images from the experimental test fields

The data collected from this activity had been centralised and analysed according to scientific literature methodologies.[14]

\section{Experimental results and discussions}

The most relevant experimental data are presented in the graphs from Fig. 6.
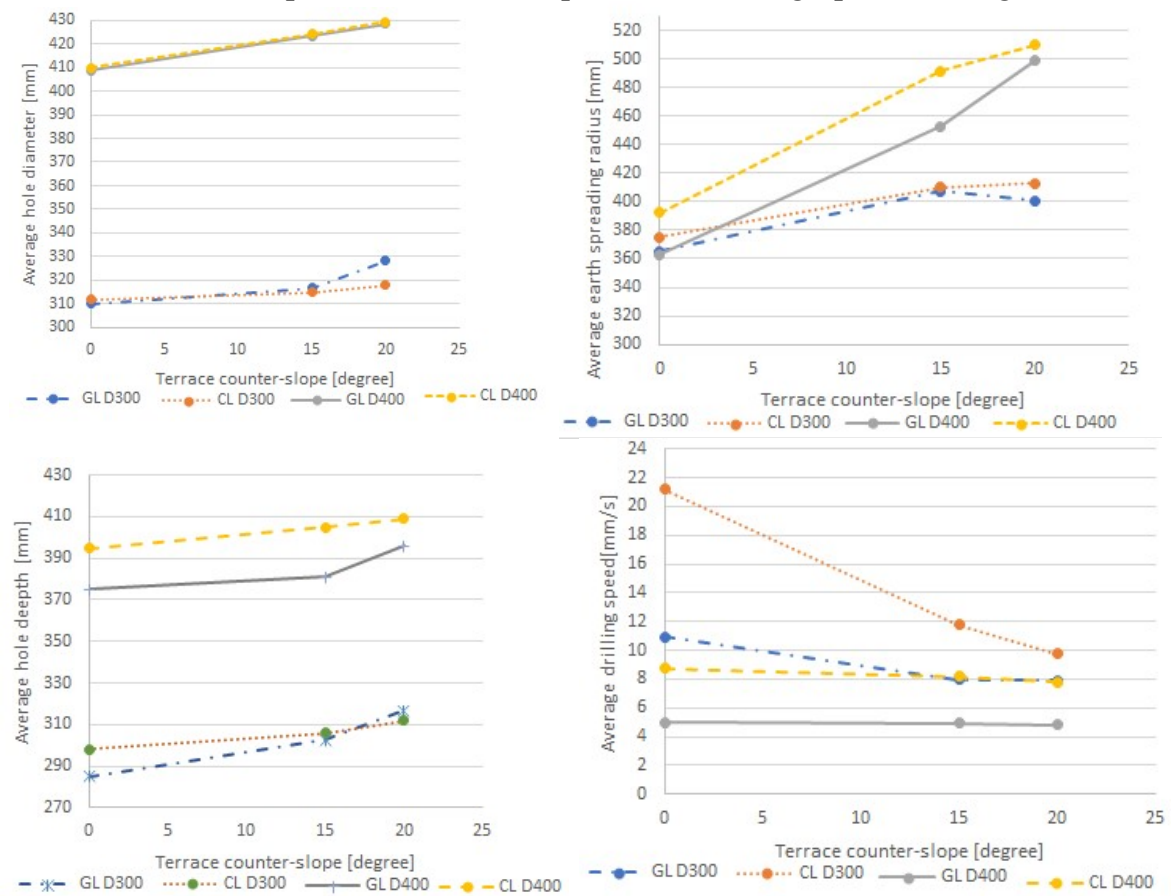

Fig.6 Most relevant working parameters determined in the field research with terrace slope. 
Appling the mathematical algorithms for drilling equipment's on the above results, were determine the qualitative exploitation indices, Table 2 . The power consumed during the working process is influenced by auger rotation moment (max. gear motor speed of output shaft) and by the transmission mechanical efficiency (that in our case it is evaluated at 0.8 ). The global specific resistance coefficient for drilling is 2 and $3 \mathrm{kgf} / \mathrm{cm}^{2}$, for CL and respectively GL, and the gear motor speed is $135 \mathrm{rot} / \mathrm{min}$.

Table 2. Estimation of BM qualitative exploitation indices.

\begin{tabular}{|c|c|c|c|c|c|c|c|}
\hline \multirow[t]{2}{*}{ Qualitative indices } & \multirow{3}{*}{$\begin{array}{l}\text { Soil } \\
\text { type }\end{array}$} & \multicolumn{6}{|c|}{ Terrace counter-slope } \\
\hline & & $0^{0}$ & $15^{0}$ & $20^{0}$ & $\mathbf{0}^{0}$ & $15^{0}$ & $20^{0}$ \\
\hline Auger diameter, mm & & \multicolumn{3}{|c|}{300} & \multicolumn{3}{|c|}{400} \\
\hline Average depth, cm & \multirow[t]{4}{*}{$\mathrm{CL}$} & 29.8 & 30.6 & 31.2 & 39.5 & 40.5 & 40.9 \\
\hline Drilling period, $s$ & & 15 & 26 & 32 & 45 & 49.3 & 52.3 \\
\hline Auger advancement, $\mathrm{cm} / \mathrm{rot}$ & & 0.88 & 0.52 & 0.43 & 0.39 & 0.37 & 0.35 \\
\hline $\begin{array}{c}\text { Auger rotation moment, } \\
\mathrm{kgf} / \mathrm{cm}^{2}\end{array}$ & & 1247.6 & 739.1 & 612.3 & 980 & 917.2 & 873.1 \\
\hline Average depth, $\mathrm{cm}$ & \multirow[t]{4}{*}{ GL } & 28.5 & 30.26 & 31.66 & 37.5 & 38.1 & 39.6 \\
\hline Drilling period, $\mathrm{s}$ & & 28.8 & 38 & 40 & 75.4 & 76.8 & 81.6 \\
\hline Auger advancement, cm & & 0.44 & 0.35 & 0.35 & 0.22 & 0.22 & 0.22 \\
\hline $\begin{array}{l}\text { Auger rotation moment, } \\
\mathrm{kgf} / \mathrm{cm}^{2}\end{array}$ & & 1087.55 & 875.15 & 869.86 & 971.71 & 969.26 & 948.16 \\
\hline
\end{tabular}

From the above results it can be concluded that, the auger rotation moment depends by soil physical-mechanical properties: the global specific resistance coefficient for drilling is $2 \mathrm{kgf} . / \mathrm{cm}^{2}(\mathrm{CL})$ and of $3.5 \mathrm{kgf} . / \mathrm{cm}^{2}(\mathrm{GL})$.

Knowing that, the rotational resistant moment $M_{v}$ of the radial augers with two radial blades mounted on two constant helices and a conical point with two helical drilling channels, can be determined the vertical resistant force $R_{v}$ that is composed from $R_{t^{-}}$earth splitter resistance force and $R_{d}$ - earth splitter deformation and displacement.

The radial forces that act on the same level plane, on auger blades, at central point are annulated, so remain only the vertical force $R_{v}$ and its moment $M_{v}$, that have the mathematical expressions from equation (1) and (2).

$$
\begin{gathered}
R_{c}=2\left[d R^{\prime}{ }_{t}{ }^{*} \sin \tau-d R^{\prime}{ }_{d}{ }^{*} \cos (\alpha+\varphi)\right], d a N \\
M_{v}=2 r^{*}\left[d R^{\prime}{ }_{t}{ }^{*} \cos \gamma_{v}{ }^{*} \cos \tau+d R^{\prime}{ }_{d}{ }^{*} \sin (\alpha+\varphi){ }^{*} \cos \gamma_{v}\right], d a N / \mathrm{cm}
\end{gathered}
$$

Where: $\alpha$ - the inclination cutting blade; $\gamma_{v}$ - the angle of upper cutting blade surface in accordance with radial direction; $\tau$ - the angle generated by $d R t$ with the suiting earth surface, and the elementary forces $d R_{t}^{\prime}$ and $d R^{\prime}{ }_{d}$ which can be calculated with equation (3) and (4), where the terms have the next signification: $k_{t}{ }^{\prime}$ - the specific resistance force of earth splitter, daN/cm; $k_{d}^{\prime}$ - the deformation force of the earth splitter, daN/cm; $d s$-the conic cutting surface length, $\mathrm{cm} ; a_{s}$ - the earth splitter section, $\mathrm{cm}^{2}$.

$$
\begin{aligned}
& d R_{t}^{\prime}=k_{t}^{\prime}{ }^{*} d s \\
& d R^{\prime}{ }_{d}=k^{\prime}{ }_{d}^{*} a_{s}
\end{aligned}
$$

Replacing the elementary mechanical measures are elaborated the equation (5) and (11).

$$
M_{v}=0.125\left(D_{b}{ }^{2}-D_{v}{ }^{2}\right) * i_{c} *\left[k_{t}{ }^{*} \sin \tau-k_{d} *\left(S / i_{c}\right) * \cos \left(\delta_{o c}+\varphi_{c}\right)\right], \text { daN/cm }
$$

Which contain the terms: $D_{b}$ - auger diameter, $\mathrm{cm} ; D_{v}$ - head diameter, $\mathrm{cm} ; \tau$ - the earth detachment splinter angle with auger horizontal plane, ${ }^{0} ; \varphi_{c}-$ the friction cuts angle with 
earth, ${ }^{0} ; \delta_{o c}-$ the upper surface cut angle with horizontal plane, ${ }^{0}$; S- the auger advances at one rotation, $\mathrm{cm} / \mathrm{rot} ; i_{c}-$ the number of auger blades. Cons derating the fact that, it is known only the vertical auger moment can be determined only one parameter at one time of earth splitter specific resistance force $k_{t}$, equation (6), which it is dependent of 3 variables.

$$
k_{t}=f\left(M_{v}, k_{d}, S\right), d a N / \mathrm{cm}^{2}(d a N / s q \mathrm{~cm})
$$

By replacing the constructive parameters for thouse two augers in the mathematical expression (6) are obtained: equation (7) for $300 \mathrm{~mm}$ auger and equation (8) for $400 \mathrm{~mm}$.

$$
\begin{aligned}
& k_{t}{ }^{\prime}=\left(M_{v} / 892.16\right) * 0.65+444.29 * k_{d} * S, d a N / \mathrm{cm}^{2}(\text { daN } / \mathrm{sq} \mathrm{cm}) \\
& k_{t}{ }^{\prime}=\left(M_{v} / 1592.15\right) * 0.65+792.89 * k_{d} * S, d a N / \mathrm{cm}^{2}(\mathrm{daN} / \mathrm{sq} \mathrm{cm})
\end{aligned}
$$

In order to draw these functions which, have to vectors $\left(M_{v}\right.$ and $\left.S\right)$ and one undefined variable $k_{d}$, it was made a mathematical assumption, $k_{d}=1$, so to this variable to be a contestant and unitary value, in order to not influence the function.

As it can be noticed in Fig.7, the $k_{d}$ evolution variates very much in cultivated land case and for large auger diameters decreases its tendency. In the case of grounded land, the variation is smaller and for big diameters is almost constant on all terrace slope, is not influenced by land inclinations.
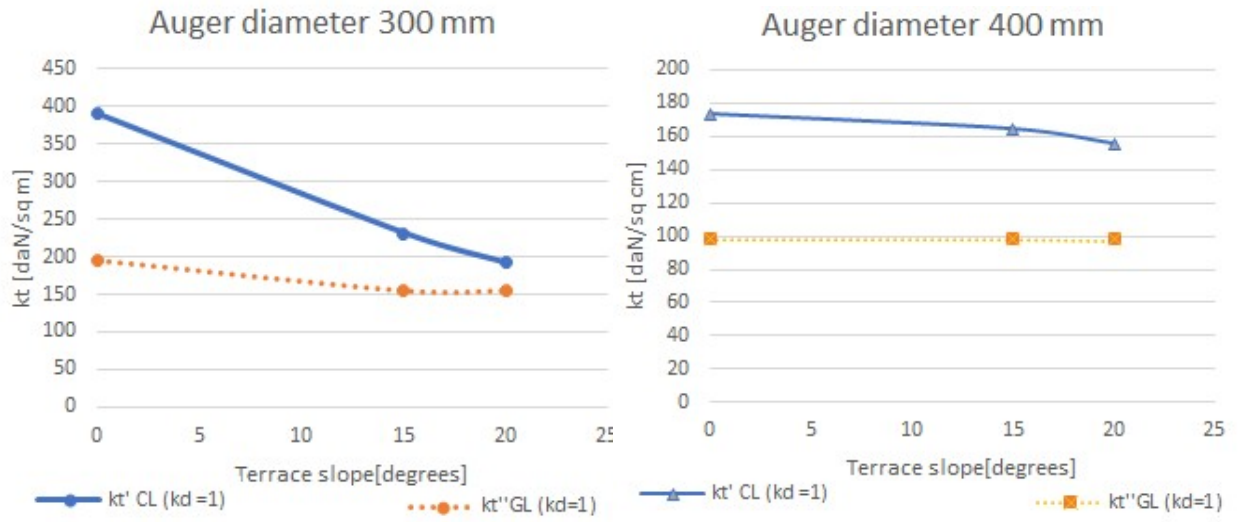

Fig.7 Dependency of $k_{t}$ function with terrace slope, when $k_{d}=1$ for different auger dimensions.

In order to draw also the dependency of earth splitter deformation force $k_{d}$, it must make the same procedure, to establish the mathematical equations from two auger type (9) and (10) and to draw the charts so the $k_{d}$ to have a minimum influence $\left(k_{d}=1\right)$.

$$
\begin{aligned}
& k_{d}{ }^{\prime}=\left(892.16 * 0.65 * k_{t}-M_{v}\right) / 444.29 * S, \mathrm{daN}_{\mathrm{cm}^{2}}(\mathrm{daN} / \mathrm{sq} \mathrm{cm}) \\
& k_{d}{ }^{\prime \prime}=\left(1592.15 * 0.65 * k_{t}-M_{v}\right) / 792.89 * S, \mathrm{daN} / \mathrm{cm}^{2}(\mathrm{daN} / \mathrm{sq} \mathrm{cm})
\end{aligned}
$$

From Fig. 8, it can be concluded that this factor has a strange evolution and for this reason must be made many other research activities for those augers and in the similar testing conditions. The correlation between $k_{t}$ and $k_{d}$ is difficult to make, because are different order of magnitude and for this reason have no intersection points. 

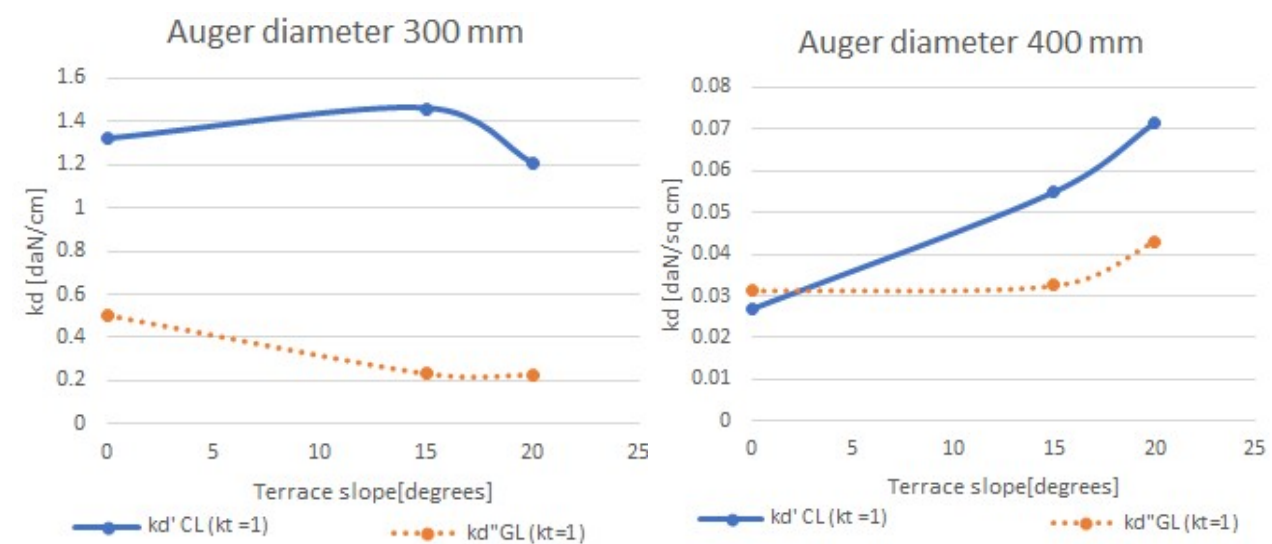

Fig.8 Dependency of $k_{d}$ function with terrace slope, when $k_{t}=1$ for different auger dimensions.

In order to determine the characteristics of auger vertical resistance force $R_{c}$, was used the mathematical expression (11) that also is influenced by $k_{t}$ and $k_{d}$, variables that are dependent between them and hard to determine in our case, because we do not have enough data, so they were replace with $M_{v}$ and after that where replaced same of the auger geometric construction parameters, and in this way was obtain the equation (12) and graphs from Fig. 9.

$$
\begin{gathered}
R_{c}=0.5 *\left(D_{b}-D_{v}\right) * i_{c} *\left[k_{t}^{*} \sin \tau-k_{d} *\left(S / i_{c}\right) * \cos \left(\delta_{o c}+\varphi_{c}\right)\right], d a N \\
R_{c}=\left[0.5\left(D_{b}-D_{v}\right) * i_{c} * M_{c}\right] / 0.125 *\left(D_{b}{ }^{2}-D_{v}{ }^{2}\right), d a N
\end{gathered}
$$
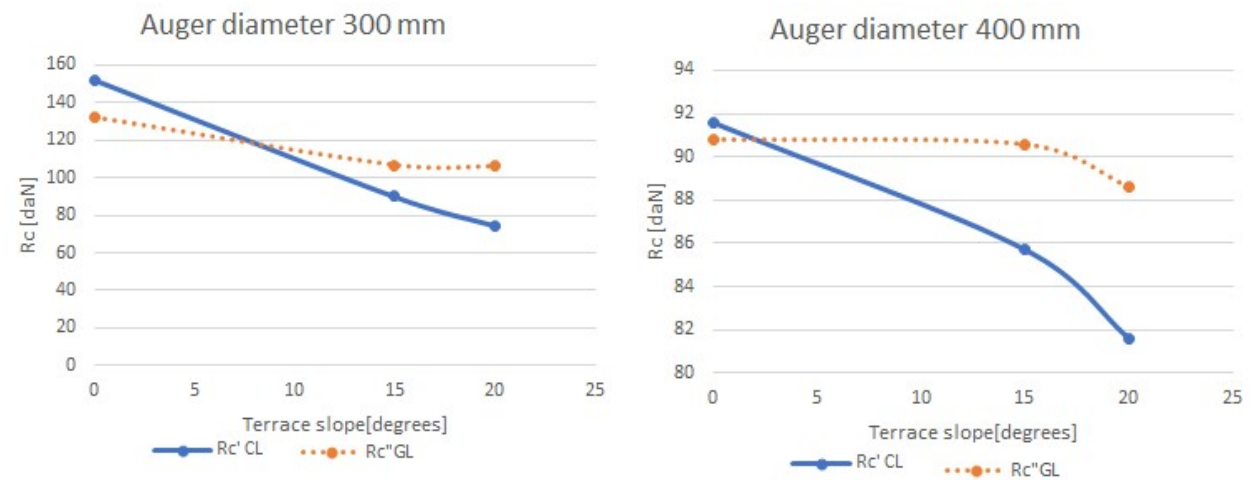

Fig.9 Dependency of $R_{c}$ with terrace slope and auger dimensions.

The $R_{c}$ has a linear tendency when the auger is working in GL condition especially for larger diameters, for CL conditions the variation is greater.

The main conclusion is that, all the values presented in this paper are influenced by the human factor, respectively by the operator physical force that is identified as $R_{V}$, and the experience of the operator in those working conditions, respectively the soil composition that mainly is the same during the exploitation. This factor also influences the power consumption and the aggregate productivity. 


\section{Acknowledgements}

This work was supported by a grant of the Romanian Research and Innovation Ministry, through Programme 1 - Development of the national research-development system, subprogramme 1.2 - Institutional performance - Projects for financing excellence in RDI, contract no. 16PFE and research was conducted on project "Integrated management of works on agricultural, wine and fruit farms", financed by NUCLEU Program - PN 191001 05 .

\section{References}

1. https://www.greenpeace.org/romania/ro/campanii/paduri/Activitati/raport-taieriilegale-2015/Date-i-cifre-despre-situaia-tierilor-ilegale-de-arbori-in-2015/;

2. http://www.wwf.ro/ce_facem/paduri/combaterea_taierilor_ilegale/?gclid=Cj0KEQ jwgODIBRCEqfv60eq65ogBEiQA0ZC5b8b2hWfNErfUQ3uYdzEP2sXZfe1TsFH8MBX57rLB-AaAiEl8P8HAQ;

3. https://www.rri.ro/ro_ro/raport_privind_taierile_ilegale_de_paduri_in_romania2586909 ;

4. http://www.wwf.ro/_core/general.cfc?method=getOriginalImage\&uImgID $=\% 26 \%$ $2 \mathrm{AB} 8 \% 2 \mathrm{~A} \% 20 \% 2 \mathrm{EW} 4 \% 0 \mathrm{~A}$;

5. https://www.scribd.com/doc/56047299/alunecari-de-teren;

6. https://stoianconstantin.wordpress.com/category/energie-eoliana/;

7. C.G. Bogdanof, A.L. Visan, D. Milea, R. Ciuperca, A.I. Petrisor, SIMI 2018 proceedings book, 127, (2018);

8. A.L. Vişan, G.C. Bogdanof, D. Milea, G.V. Ciobanu, AGIR Buletin no.4, 62, (2016);

9. A.L. Vişan, G.C. Bogdanof, D. Milea, G.V. Ciobanu, C. Mircea, HERVEX Proceeding, 383, (2016);

10. C.G. Bogdanof, V. Moise, A.L. Visan, G.V. Ciobanu, Engineering for rural development, Jergava, 653, (2017);

11. C.G. Bogdanof, A.L.Vişan, A. Paun, D. Milea, OSIM patent application A0075,(2016)

12. C.G. Bogdanof, A.L. Visan, G.V. Ciobanu, A., D. Milea OSIM patent application A01001/12.12.2016

13. C.G. Bogdanof, A.L. Vişan, A. Păun, Milea D. OSIM patent application A0056, (2017)

14. C. Ciocirdea, Masini de spat gropi, Creres Publisher,51, (1973); 